\title{
A CRISE DAS IDENTIDADES NA AMÉRICA LATINA
}

Jonas Silva Abreu ${ }^{1}$

\section{RESUMO}

Em 1995, foi publicado o livro "Consumidores e Cidadãos" de Nestor Garcia Canclini. O livro trazia como tema a globalização e o consumo como agentes das transformações ocorridas no processo de elaboração das identidades coletivas no espaço latinoamericano. Tendo este texto como marco histórico-reflexivo, o objetivo do artigo é decifrar quais identidades foram produzidas no continente e entender a construção e negociação destes valores. Com o auxílio de outras obras, as identidades serão descritas tanto no contexto tradicional da modernidade constatadas na formação dos estados, nações e partidos políticos, mas também na ambiência multicultural da pósmodernidade que se fazem presentes nos discursos étnicos, atitudes religiosas e movimentos sociais em diferentes subgrupos. $\mathrm{O}$ trabalho pressupõe ainda que rádio, cinema, televisão e mais recentemente as redes de tecnologia e cultura transnacionais são meios que ajudaram a construir e alterar as identidades na região, além de elaborarem imagens e discursos sobre elas.

Palavras-chave: Globalização. Consumo. Identidade latinoamericana. Cultura transnacional.

${ }^{1}$ Mestre em Produção cultural pela FGV (Bens culturais e projetos sociais), especialista em marketing estratégico pela UCAM, com formação em turismo pela UniverCidade. Professor de graduação e pós-graduação em Marketing,Gestão e Produção de eventos e Turismo, na Universidade Estácio de Sá. 


\section{ABSTRACT}

\section{THE CRISIS OF IDENTITY IN LATIN AMERICA}

In 1995, the book "Consumers and Citizens" by Nestor Garcia Canclini was published . The book brought up the topic of globalization and consumption as agents of the transformations occurring in the process of elaboration of collective identities in the Latin American area. Having this as a historical text, a reflective marker, the objective of this article is to decipher which identities were produced on the continent and understand the construction and negotiation of these values. With the aid of other works, identities are described in the traditional context of modernity in the formation of states, nations and political parties, but also in multicultural ambience of postmodernity that are present in ethnic discourses, religious attitudes and social movements in different subgroups. The work assumes that radio, film, television and more recently technology networks and transnational culture are media who helped build and change identities in the region, and develop images and discourses about them .

Keywords: Globalization. Consumption. Latin American identity. Transnational culture. 


\section{Introdução}

Até meados do século $\mathrm{XX}$ as identidades se organizavam a partir dos símbolos nacionais produzidos no interior da nação. As dúvidas mais comuns dos cidadãos, como a que lugar pertenço, que direitos possuo neste lugar, onde posso obter informações ou quem me representa, podiam ser mais facilmente respondidas, uma vez que a sociedade se estruturava em torno do Estado, dos partidos políticos ou dos sindicatos. A arte, a literatura e as tradições eram responsáveis por reforçar esse senso de participação coletiva e todos se reconheciam como cidadãos de certo país, de uma nação ou de uma ideologia tendo como ponto de partida aquelas expressões culturais geralmente combinadas com alguns de seus mitos de origem.

Nas últimas décadas do século XX este processo tem se transformado. As identidades se organizam cada vez mais em torno de símbolos transnacionais. No caso específico da América Latina, isto pode significar que tanto os ícones da mídia, como Hollywood, BBC ou Televisa, como os que são materializados no consumo de marcas globais como Nike, Apple e Microsoft, ou ainda aqueles elaborados a partir dos produtos culturais de corporações desterritorializadas, como o Cirque de Soleil, são capazes de estimular níveis de identificação e sensos de pertencimento globais, em detrimento dos elos que mantinham certos níveis de cultura e interatividade locais.

Neste caso, é de se supor que as perguntas sobre pertencimentos e identidades não sejam mais respondidas pelos partidos e sindicatos, ou pelos líderes e intelectuais que forjaram as identidades nacionais no continente. Sabemos que este não é um fenômeno exclusivamente latinoamericano, mas as regras abstratas da democracia ou a participação cooperativa em instituições estão cada vez mais desacreditadas na região e não conseguem responder às mudanças culturais das novas formas de fazer política. As campanhas eleitorais migraram para a televisão e hoje alcançam a internet e as polêmicas ideológicas são substituídas pelos confrontos de imagem e técnicas de marketing pessoal, em meio ao surgimento de "novos" modelos políticos.

Como resultado são identificados vários deslocamentos das identidades tradicionais mediante as transformações da tecnologia e da cultura ou potencializados por velhas demandas identitárias. Neste último caso, estes anseios podem ter origem em diversos sensos de pertencimento: baseados em tradições indígenas milenares, como as que ocorrem no complexo mesoamericano e na área andina, ou aqueles influenciados pela força de novos discursos ideológicos como na Venezuela, Bolívia e 
Nicarágua ou ainda potencializados por movimentos afros e causas indígenas no Brasil.

Outros fenômenos de pertencimento ocorrem em meio ao modo neoliberal de globalização e se desprendem destas rearticulações do tradicional, geralmente estimulados pela força transformadora de movimentos sociais como tem ocorrido no Chile e Brasil. Abrangem também os discursos das populações periféricas, das mulheres, dos gays e até das novas expressões religiosas neopentecostais metropolitanas.

Como se pode perceber melhor estas transformações? Analisando as mudanças que ocorrem na vida cotidiana das grandes cidades latinas, a reorganização da esfera pública gerada pela indústria da comunicação e cultura, e os impactos decorrentes de uma globalização cada vez mais acentuada, é que se poderá descortinar esses novos conflitos multiculturais, que agravam alguns dos velhos problemas de identidade e indicam novos sensos de pertencimento.

Em primeiro lugar, defendemos que a globalização como agente deste novo processo de deslocamento das identidades tradicionais, como poder ser visto na experiência latina, deve ser analisada tendo em vista o fracionamento social e econômico da região e não como um processo de homogeneização cultural, que seria a raiz da "crise nas identidades" pela qual estaríamos passando, como muitos ainda acreditam.

Muitos defendem que não se pode falar de homogeneização na globalização, porque as diferenças e desigualdades encontradas nas sociedades latinas são rearticuladas, e não inteiramente suprimidas por uma tendência "imperialista" ou totalizadora. As sociedades podem ser pressionadas a absorver valores e crenças globais e de todos os modos sucumbem a elas, mas as diferenças ganham significados próprios e se reinventam em pertencimentos cada vez mais peculiares articulados nas novas relações de comunicação e cultura.

Mais recentemente, estas transformações estão sendo estudadas sob o enfoque das relações de consumo que organizam teias de consumidores para indicar um cidadão em busca de novos pertencimentos. Afinal, quando selecionamos e nos apropriamos dos produtos definimos os valores públicos que estes produtos nos proporcionam assumir. O modo pelo qual nos distinguimos na sociedade e combinamos aquilo que é ao mesmo tempo, prático e atrativo, não se coloca apenas como questão de eficácia comercial. E a globalização não deve ser vista apenas, como o modo de ampliar mais rapidamente as vendas. Como se vê, os cidadãos se organizam cada vez menos em torno dos símbolos nacionais, continuam buscando pertencimentos étnicos e culturais fora da nação e 
do Estado, mas a verdade é que se organizam cada vez mais como redes de consumidores.

Identificar essas transformações não significa aceitar a desconstrução da cidadania no consumo e nem mesmo que as nações se descaracterizem na globalização. Escolhemos falar aqui de uma recomposição das novas estruturas globais e somar às investigações empíricas necessárias uma melhor compreensão do fenômeno.

Inicialmente tentaremos analisar a base teórico-conceitual que interpreta as transformações estruturais ocorridas durante o processo de formação das identidades dos sujeitos e verificar sua relação com os deslocamentos ocorridos na América Latina. Em segundo lugar, demonstraremos como este processo está fracionando as cidades latinas, já que elas constituem o campo tangível no qual se expressa a batalha das identidades modernas. E por fim, poderemos discutir como as monoidentidades nacionais latinas caminham na direção do multiculturalismo global pós-moderno.

\section{A estrutura dos deslocamentos de identidade}

$\mathrm{Na}$ busca de uma base segura para examinar essas transformações, propomos uma pergunta: de que maneira a questão do deslocamento das identidades está sendo discutida no campo teórico social a partir de novas abordagens teórico-metodológicas? A partir dos pesquisadores que estudam as identidades modernas, há um grupo que destaca o progressivo colapso das identidades, e o argumento é de que as sólidas estruturas que nos localizavam como indivíduos sociais estão se fragmentando.

Essa abordagem denominada de "descentração do sujeito" foi estudada, entre outros, por Stuart Hall (2006) e basicamente é organizada tendo em vista a fragmentação das paisagens culturais de classe, gênero, sexualidade, etnia e nacionalidade que abala a ideia que tínhamos de nós mesmos como sujeitos integrados. Os trabalhos de Hall, baseados em uma intensa pesquisa e fundamentação no campo dos estudos sociais, o transformaram em um dos maiores estudiosos da identidade cultural na modernidade, como professor da Open University, Inglaterra. Foi também um dos fundadores e diretores do Centre for Contemporary Cultural Studies de Birminghan.

Hall aponta três concepções de sujeito, do qual derivariam as identidades: o sujeito iluminista, baseado na ideia de um indivíduo centrado, unificado e dotado de consciência e de ação, formalizado a partir das ideias da Ilustração no século XVIII. Segundo esta concepção, o núcleo 
interior do sujeito emergia ao nascer, e mesmo se desenvolvendo, continuava idêntico a ele, isto é, o centro essencial do "eu" era a própria identidade de uma pessoa. É bom reforçar que estas ideias sobre o sujeito iluminista foram sendo estruturadas gradativamente por alguns filósofos desde John Locke (1632-1704), que acreditava no conhecimento acumulado do homem através do empirismo, passa pelos inspiradores da Revolução Francesa, como Voltaire (1694-1778), que defendia a liberdade de pensamento e não poupava críticas à intolerância religiosa; Rousseau (1712-1778), que acreditava na ideia de um estado democrático que garantisse igualdade para todos; Montesquieu (1689-1755), que defendeu a divisão do poder político em Legislativo, Executivo e Judiciário e culmina em Diderot (1713-1784) e Jean Le Rond d'Alembert (1717-1783), que ajudaram a difundir essas teorias quando elaboraram a Encyclopédie, um vasto compêndio dos conhecimentos e pensamentos filosóficos, bem com das tecnologias do período, descrevendo os instrumentos manuais e os novos dispositivos da Revolução Industrial na Inglaterra.

Esse processo formador da consciência iluminista, tomado em conjunto, foi se modificando e ainda está se transformando. Assim, o sujeito sociológico do século XIX altera em parte o sujeito iluminista, reflete a complexidade do mundo externo e limita essa suposta autonomia e autossuficiência do indivíduo, uma vez que modelava a sua identidade de acordo com a interação entre o indivíduo, o Estado e as instituições que o representavam.

Essa concepção interativa da identidade e do "eu" foi pesquisada por Mead (1934) que demonstrou que os egos das pessoas são produtos sociais, sem deixar de ser propositados e criativos. Outro estudioso na área, Blumer (1937), criador do termo "interacionismo simbólico" e intérprete de Mead, pôs em evidência as principais perspectivas dessa abordagem: as pessoas agem em relação às coisas baseando-se no significado que essas coisas tenham para elas e esses significados são resultantes da sua interação social e modificados por sua interpretação.

Finalmente, quando Stuart Hall define o sujeito pós-moderno, ele quer dizer que este não seria composto de uma, mas de várias identidades, algumas vezes contraditórias ou mal resolvidas. Uma identidade assim, poderia ser formada e transformada continuamente em relação às formas pelas quais somos representados ou confrontados nos sistemas culturais que nos rodeiam.

Então, como era de se esperar, quando falamos de "crise das identidades", talvez estejamos nos referindo à crise do sujeito sociológico que antes era pleno desta cômoda história dele mesmo, enquanto sujeito 
nativo de um país, defensor de sua ideologia e consciente de seus direitos. Agora na dimensão pós-moderna, enquanto os sistemas de significação se multiplicam, este sujeito é confrontado com uma diversidade desconcertante de identidades possíveis.

Propomos então para a América Latina a análise de como estas transformações da identidade se associam e causam impactos na identidade cultural local. Nossa proposição nos remete a ideia de que na América Latina, estas identidades estáveis caracterizadoras do sujeito sociológico foram forjadas no Ocidente durante os séculos XVIII e XIX, de forma inequívoca nas capitais europeias, na medida em que se transformavam em centros de representação política e cultural da nação moderna.

Nossa principal questão aqui é a maneira pela qual o sujeito sociológico teria sido ajustado nesta parte do mundo para elaborar o sujeito pósmoderno. Esta passagem se deu à medida que as nações europeias e os EUA que haviam mediado para o sujeito latino os valores e sentidos do mundo que ele habitava, viam esses símbolos serem deslocados. Como Hall (1987) insistiu nisso, também faremos o mesmo: permanecendo a estrutura da identidade aberta, o sujeito sociológico modelado pela Europa e EUA teria sido transformado por uma pluralidade de posições de sujeito.

Precisamos de outro autor aqui, para nos ajudar nesta análise. Canclini (1995) é um dos que mais estuda esta relação entre identidade, globalização e cultura e como ele tem suas pesquisas circunscritas à America Latina, vamos utilizar seus estudos para nossas proposições, mas considerando que esse novo contexto no qual são discutidas as questões de identidade, tem uma validade mais abrangente.

$\mathrm{Na}$ busca por um esclarecimento de como foram modeladas as identidades tradicionais na porção ibérica do continente americano, ele reforça a ideia de Hall, quando afirma que a América Latina foi "inventada" pela Europa em um contínuo processo colonizador que se iniciou com Espanha e Portugal, mas que logo foi reelaborado por França e Inglaterra. Essa relação de dependência foi acentuada com 0 deslocamento do eixo hegemônico mundial para os EUA, no início do século XX. Essa mudança de subordinação foi acompanhada de profundas alterações nos mercados industriais, financeiros e agrícolas, alem de influir nos movimentos populacionais e no consumo de tecnologia e cultura. 
Em um de seus livros mais excitantes "Consumidores e Cidadãos", Clanclini analisa este assunto baseado em quatro eixos: as cidades, os mercados, a ligação tecnologia-cultura e os deslocamentos de população.

Todos estes fatores seriam ligados por uma intensificação das relações econômicas e culturais entre a América Latina e os Estados Unidos, que ao longo do século XX acabou substituindo parcial ou totalmente muitas das relações tradicionais com a Europa que vigoravam desde o século XVI até a Primeira Guerra Mundial.

Bem, nossa suspeita é que mesmo seguindo as pistas de Nestor Canclini, quando interpreta que os deslocamentos de identidade na América Latina tenham sido consolidados em torno de corporações americanas, precisamos fazer alguns ajustes nesta análise. De fato, duas décadas depois, ESPN, Playstation, Apple ou Google, constituem um recurso simbólico de prestígio para as marcas e valores americanos, mas a novidade é que também devemos acrescentar novos players transnacionais, de diversas origens, que atuam na América Latina e que dividem este bolo: Sony, Dascom, Siemens, China Telecom, Televisa, Globo, Nokia, entre outros. Então, devemos reconhecer que na América Latina outras corporações impregnadas com suas "nacionalidades" originais (japonesa, alemã, chinesa, brasileira ou finlandesa), nos auxiliam no diagnóstico que redefine outros sensos de pertencimento na região.

É preciso reconhecer também que este processo é tanto conduzido pelas corporações internacionais, em termos de seus produtos diretos, como por expressões que surgem das extensas redes de comunicação social associadas ou não a estas empresas. De forma cada vez mais elaborada se organizam comunidades como: jovens em torno do rock ou da funk music, telespectadores do "The Voice", fãs do seriado Chaves, associados do Facebook ou voluntários do Greenpeace.

Quando fazemos nossas escolhas nesta área de consumo cultural, revelamos os sistemas simbólicos que nos influenciam e nos identificam a um produto específico. Muitos destes valores estão impregnados de relações entre o nacional, o continental e o global. Nossa linha de pesquisa sobre "globalização e conflitos multiculturais", tem se ocupado, entre outros fatores, de estudar como as pessoas na América Latina percebem os efeitos dos sistemas de significação corporativa nos meios de comunicação, e como isso afeta os seus sensos de pertencimento nesta região.

Vamos à uma ilustração para corroborar este fato? Quantos telespectadores brasileiros associam o programa de TV "The Voice" à 
sua matriz americana? Supondo que tenhamos uma boa porcentagem que faça essa associação, este é um fator relevante para determinar suas escolhas ou auferir padrões de qualidade? Desconfiamos que não. É possível que constatemos que no jogo das identidades híbridas, conforme exposto por Canclini e Hall, a escolha leve em conta tanto o "padrão americano de qualidade" como os apelos por um conteúdo "nacional". Por outro lado, a escolha pela versão "brasileira" não passa apenas pela valorização da música de origem, pois outros fatores estéticos, visuais e emocionais são somados nesta equação, desfazendo a velha dicotomia de cultura americana versus cultura brasileira. É notável a contradição do que registramos aqui. No caso do "The Voice", o seu consumo seria uma experiência exercida de forma emotiva tanto quanto está impregnada de ideologia.

Deve-se ter em mente que estes questionamentos são simplificações, apenas para situar este caráter de mudança na modernidade e confirmar a tese de que a identidade unificada, segura e coesa do sujeito sociológico é uma fantasia, e que no desenvolvimento das informações e dos argumentos se tornam mais densos.

Se há alguma conexão em toda essa racionalidade econômica que confronta os interesses das corporações, as redes de tecnologia e as identidades culturais, ela vem se materializando nas relações de consumo. Não se deve esquecer que quando o consumidor seleciona os bens e serviços que vai adquirir ele define o que será publicamente valioso e os diversos modos de distinção e integração. Como essa articulação não existe do ponto de vista formal, foram concebidas outras maneiras de se informar, entender as comunidades e de se exercer os direitos através da industrialização das tecnologias audiovisuais de comunicação.

Suspeitamos que neste novo cenário sociocultural na América Latina centrado no "redimensionamento das instituições", ou seja, na perda de influência dos órgãos locais em detrimento dos conglomerados empresariais globais, prevaleça um reordenamento da convivência urbana com o predomínio dos bens e mensagens globalizados tornando o cidadão mais preocupado em desfrutar qualidade de vida do que ser representante de uma opinião.

Isso agrava particularmente o contexto da indústria cultural na região, uma vez que no caso da América Latina, seus centros de produção para a arte, cultura e publicidade são pouco representativos, mas seus centros de consumo para as novidades internacionais se destacam potencialmente: Rio de Janeiro, Buenos Aires, Santiago, Cidade do México e São Paulo sediam espetáculos internacionais, tornam-se mercados consumidores 
para empresas transnacionais em segmentos como telefonia, publicidade digital, games e TV por assinatura, além de atrair investimentos multinacionais em petróleo, turismo e indústria aeroportuária.

Isso provoca o debate sobre como o acesso simultâneo aos bens materiais e simbólicos não está vindo acompanhado de um pleno exercício da cidadania. Se a mídia está servindo a um modelo de espetacularização da cultura e da informação em substituição aos debates de interesse público, é notório concluir que a ela pertencem as decisões do que vai emitir ou não ao cidadão.

O consumo está atrelado às disputas que os grupos sociais desenvolvem por aquilo que se produz e pelos diversos modos de utilização e publicidade do uso desses bens. As mercadorias serviriam assim, para pensar, já que carregadas de significados, rituais e celebrações que regulam a vida social de determinado grupo, exercem função de distinção e comunicação, alterando o conceito de que apenas são úteis para a expansão do mercado e a reprodução da força de trabalho.

Uma ilustração nos ajuda nesta questão. Canclini defende a ideia que os seres humanos intercambiam objetos como necessidades culturais de distinções, desejos e reflexões. Nas diferentes fases deste intercâmbio em que os objetos culturais se inserem, no início, sequer são mercadorias, como no caso das máscaras feitas por indígenas mexicanos para lembrar dos antepassados, dos rituais e das tradições. Depois, numa provável fase mercantil, suas réplicas podem ser vendidas aos turistas. Em seguida, quando se instalam no museu, se esquece seu valor econômico.

O que moveria os indígenas a aceitarem a comercialização senão o fato de que representa um valor compartilhado? A introdução de objetos ou a transformação da utilização destes objetos em souvenires comerciais é aceita desde que sejam acolhidos pela lógica comunitária. Observamos que o consumo privado dos bens e dos meios de comunicação estão oferecendo respostas aos cidadãos quanto às questões relacionadas aos seus direitos, interesses e pertencimentos.

Desta forma, o consumo é eminentemente social e correlativo, ou seja, pode-se ter uma combinação de padrões com informações a respeito de produtos e serviços, que carregados de crenças e juízos, possibilitam a cooperação entre vendedores e compradores em termos dos seus significados e dos seus valores de representação. Em que nível se evidencia essa colaboração nas cidades latinas? Falamos em cidades, porque é nelas que se concentram estas negociações transnacionais na formação das identidades. 


\section{O consumo serve como árbitro nos conflitos de identidade nas cidades latinas.}

Como núcleo de vida política, comercial e artística, as cidades da América Latina, durante o século XX, foram se distanciando de sua matriz europeia, em favor das metrópoles americanas, em meio ao cenário de reestruturação transnacional dos mercados de bens materiais e de comunicação. Aliás, Canclini admitiu que estas metrópoles sequer são cidades como Stanford, Duke, Disneyworld ou o [Mall of America].

Canclini ressalta, entretanto que o fracionamento das megacidades latinas (ele usa o termo desintegração) não é fruto de imposições imperialistas nem cópia da urbanidade americana, mas fruto de desigualdades internas no processo de absorção da experiência transnacional, que originaram "urbes" degradadas que embora expansivas no mercado de consumo, possuem insuficientes políticas de habitação e deterioração da qualidade de vida, como Cidade do México, São Paulo ou Bogotá. Pode-se constatar um certo nível de padronização quanto aos modelos globais de tecnologia e consumo de entretenimento nestas cidades, mas nos deparamos com uma rearticulação dos mercados de bens simbólicos, dependendo da negociação entre as elites internas e externas e da influencia das culturas populares.

Enquanto essa pluralidade vai se construindo, é natural que se diluam as lealdades nacionais, mas os setores hegemônicos de uma determinada nação desenvolverão afinidades com as comunidades externas hegemônicas e não com os setores subalternos de sua própria nação. Isso nos levaria a rejeitar a ideia de "homogeneização" (CANCLINI, 2006, p. 69).

Um exemplo interessante para confirmar essa remontagem, pode ser encontrado na indústria televisiva: em uma mesma área urbana, enquanto alguns se identificam com Santana, Justin Bieber, Sting ou Carlos Fuentes, outros mais apegados às "raízes latinas" preferem Julio Iglesias, Alejandra Guszmán e as telenovelas venezuelanas ${ }^{2}$. No Brasil, os adeptos do pop-rock podem estar antenados ao Grammy e à MTV ou preferir o "The Voice" original. Outros, no mesmo bairro, podem ter afinidade com o funk e axé music e se conectarem ao "Big brother" ou "The Voice Brasil".

2 A lista original de Nestor Canclini foi modificada para uma interpretação mais adequada ao momento em que foi escrito este artigo. 
Nossa tese é a seguinte: os dois grupos reforçam que as conexões culturais formadoras das convicções e escolhas são construídas tanto localmente como também originadas dos fragmentos de consumo privado de cultura internacional. Renato Ortiz (1996) identifica para esse caso, o que se pode chamar de "cultura internacional-popular" a partir da construção de símbolos transnacionais. Os aspectos da globalização e da modernidade para os países "periféricos" seriam perversos, selvagens, mas reais. Segundo Ortiz, a globalização provoca um desenraizamento dos segmentos econômicos e culturais das sociedades nacionais, integrando-os a uma totalidade que os distancia dos grupos mais pobres, marginais ao mercado de trabalho e de consumo.

Quando estudou o processo de mundialização das cidades e da cultura, ele constatou que ocorre por dois motivos interligados: o avanço tecnológico e o compartilhamento universal de objetos. Assim, pelas redes de tecnologia as corporações transnacionais com seus produtos mundializados e suas marcas facilmente identificáveis se tornaram referências no espaço mundial mediados pela cultura de consumo e a publicidade.

A disseminação desses objetos se justifica quando pensamos em diminuição de custos por parte das empresas. Cada peça, independente do lugar que venha, deve ser adquirida no momento da montagem de tal forma ao final o lucro seja o maior possível.

Algumas pistas da cultura internacional-popular voltada para o mercado consumidor unificado e internacional podem ser encontradas em eventos esportivos como a Copa do Mundo realizada nas cidades brasileiras. No elenco de atrações do show abertura podem existir ginastas acrobatas e de trampolim, capoeiristas e pernas-de-pau, mas após a apresentação dos bailarinos e das riquezas do Brasil, o espetáculo é encerrado com a performance da música oficial da Copa do Mundo da Fifa, "We Are One", pelo rapper cubano-americano Pitbull, a cantora portoriquenha Jennifer Lopez, a brasileira Claudia Leitte e o Olodum.

Por causa disso, é de se supor que o processo criativo da América Latina é protagonista do consumo transnacional, mas não de sua produção, visto que a reorganização dos sistemas simbólicos funciona em torno de grandes conglomerados multinacionais que visando ao lucro pode conferir a competência de decisão às elites selecionadas. Qual seria então o impacto nas questões de identidade, nesta região, a partir desta reestruturação simbólica entre as corporações e o consumo?

Nestes conglomerados, uma das maneiras de pensar o consumo é tratá-lo como uma forma de distinção social e vincular a sua abordagem aos 
preceitos do marketing global. Essa dinâmica pode ter sido esquadrinhada pela primeira vez na obra Multinational Marketing Management, escrito por Warren Keegan e Mark Green, que abriu novos caminhos no campo de marketing internacional quando foi publicado em 1974. Depois, em "Princípios de Marketing Global” (1997) a intenção foi desenvolver nas universidades a ideia de regionalização global, ou seja, o profissional de marketing deveria "pensar globalmente e atuar localmente".

Assim se reproduz no pensamento estratégico de marketing o que ocorre com as cidades de modo geral em termos das trocas culturais realizadas através dos processos globais internos e externos que se operam nelas. Não se trata aqui de fazer correspondência à ideia difundida por Theodore Levitt em seu famoso artigo de 1983, na Harvard Business School $^{3}$ de que os profissionais de marketing tinham diante de si uma "aldeia global homogênea". Alguns críticos de Levitt, apressaram-se em dizer que uns poucos produtos se prestavam ao marketing global, e um deles seria a Coca-Cola. Parece notório que a eficácia da Coca-Cola não se deveu à padronização total dos elementos do composto de marketing. O sucesso da Coca Cola na América Latina e em toda a parte, teria sido consequência de sua capacidade de chegar à "regionalização global", de sua habilidade de ser um produto local tanto quanto os originais, mas aproveitando, ao mesmo tempo, as vantagens de operações em escala global.

Anthony Giddens (2008), sociólogo britânico que dedica grande interesse na reformulação da teoria social e no reexame da compreensão do desenvolvimento da "modernidade", assegura que as organizações modernas apresentam uma habilidade de conectar o local e o global que seriam impensáveis nas sociedades tradicionais. Embora já existisse nas civilizações pré-modernas, Giddens acrescenta que nas sociedades modernas, o dinheiro possibilita as trocas que independem de modos de representação, transformando-se mais recentemente em números num computador e isso torna as condições de desencaixe proporcionadas pelas economias contemporâneas muito mais amplas do que ocorria anteriormente.

Para Giddens, portanto a modernidade já era implicitamente globalizante. Seguindo esta linha de raciocínio quem se voltar ao estudo de identidade,

\footnotetext{
3 Theodore Levitt usou a palavra "globalização" pela primeira vez em 1983, em um artigo intitulado "A Globalização dos Mercados" pela Harvard Business Review. No artigo, podemos identificar os princípios da convergência dos mercados do mundo e uma certa padronização dos processos de venda. O termo ganhou popularidade em 1990, com a publicação do livro "O Mundo Sem Fronteiras: Poder e Estratégia na Economia Interligada”, de Kenichi Ohmae.
} 
consumo e cultura nas cidades latinas, atualmente, deve se preocupar com os fatos que ocorrem numa vizinhança local e observar como são influenciados por variáveis operadas a uma distância indistinta daquele espaço. Isso confirma que vamos encontrar uma cultura transnacional convivendo ao lado de uma cultura local. Esta pode se alimentar de posições étnicas e religiosas, mas aquela se constata mais verificável nas questões de consumo e de desenvolvimento econômico internacional. Não podemos deixar de esclarecer que a cultura local pode ser individualizada e customizada, sem perder muito suas características gerais. Quanto à cultura transnacional, as redes de tecnologia e finanças induziram mercados digitais globais que se tornaram as principais indutoras para a construção desta cultura globalizada.

Para compreender melhor este fenômeno, retomando o sentido de Ortiz, é necessário ressaltar que a maior parte das percepções e dos valores construídos em fragmentos vindos de todas as partes foi possível com o advento das indústrias culturais (cinema, música, publicidade) originados ou operados a partir das corporações europeias e americanas, que teriam coberto todos os países aproximando-os de uma cultura internacional. Apesar disso, na paisagem cultural latina ainda permanecem em meio a essa engrenagem fragmentada internacional, várias interações interculturais que incluem desde exaltações de tradições locais à readaptações das identidades em atitudes cada vez mais ecléticas.

Canclini também fez muitos estudos sobre isso na Cidade do México, mas com uma preocupação intrigante: suas pesquisas permitiram identificar que quando estas formas de exaltação das culturais locais se tornam mais evidentes, não é por meio das representações políticas ou institucionais, uma vez que estas entraram em crise, mas prevalecem em agrupamentos setoriais subordinados a paternalismos milicianos ou religiosos. Os "corporativismos familiares" ou "bairristas" e as "associações cívicas" identificadas no estudo dos pesquisadores Guilhermo de la Peña e René de la Torre, em Guadalajara, ${ }^{4}$ são citados para corroborar esse diagnóstico. Além da cidade industrial e da cidade histórica, existe a cidade globalizada conectada com as redes mundiais financeiras e informacionais o que coloca os estudos urbanos focados sobre identidade não mais no processo de industrialização e suas consequências na rede tecnológico-cultural, mas nos sistemas de comunicação e finanças.

É possível verificar que em megalópoles como Cidade do México, São Paulo ou Buenos Aires a expansão dos equipamentos culturais não

\footnotetext{
${ }^{4}$ Ver a pesquisa e a análise que os autores elaboraram na revista Ciudades (Cidades), no texto "Identidades urbanas al fin del milenio" publicada no México, entre abril e junho de 1994.
} 
acompanhou a disseminação da área metropolitana, observando-se uma baixa frequência da população nos centros de consumo. Os problemas que afetam esta população "metropolitana" referem-se mais aos distúrbios provocados por ambulantes, às festas do padroeiro do bairro ou às demandas por transporte público, saúde e segurança da sua região.

Estes territórios mais atomizados, porém conectados aos valores transnacionais através dos meios de comunicação, constroem um tecido de racismo peculiar. O preconceito contra os indígenas na Cidade do México ou os nordestinos em São Paulo ${ }^{5}$ permite concluir que reações mais extremistas encontram-se arraigadas nas metrópoles como uma recusa ao pensamento igualitário, que muitos acham abstrato.

A desagregação das culturas tradicionais, porém é fato notório e as novas conexões eletrônicas utilizam um discurso eficiente: o tango da Argentina, o samba do Brasil ou a salsa do Caribe servem às coproduções internacionais para alcançar públicos amplos, mas as referências nacionais e os modos locais se diluem em seriados e filmes que são os mesmos em São Paulo, Tóquio, Londres ou Cidade do México. Isto se dá porque a vida social urbana se organiza cada vez menos nos centros históricos e cada vez mais nos centros comerciais, como shoppings, que se parecem no mundo todo. Configura-se uma desterritorialização com a diminuição dos vínculos ao lugar ou à história onde habitam as pessoas próximas.

Se a literatura, as artes e o folclore foram os construtores dos signos diferenciadores das nações até o século XX, a televisão, a publicidade e mais recentemente a internet mesclaram-se aos códigos tradicionais para formação das identidades e geraram textos e repertórios iconográficos produzidos por estes meios e veículos de comunicação através da globalização da vida urbana.

Nas grandes cidades latinas, despedaçadas pelo crescimento vertiginoso e convivendo com um multiculturalismo, ao mesmo tempo integrador e conflitante, diminui-se o impacto das manifestações capitaneadas por sindicatos, partidos ou por discursos nacionalistas e entram em cena os movimentos sociais urbanos, estilhaçados e fugazes.

\footnotetext{
${ }^{5}$ Canclini cita estudos de Antonio Flávio Pierucci sobre o racismo antinordestino em São Paulo, especialmente no episódio da busca de uma explicação da derrota de Fernando Henrique Cardoso quando apresentou sua candidatura à prefeitura de São Paulo, em 1985. Descobriu-se que um dos motivos do voto conservador era o preconceito contra o migrante nordestino identificado como responsável pela decadência da cidade.
} 


\section{A negociação das identidades na América Latina: integrar ou reagir?}

Este panorama traçado até aqui se organiza em meio ao que Hall chama de "modernidade tardia", numa linha cronológica indefinida, ainda que muitos percebem estas manifestações em um contexto inserido como "pós-modernidade" desde as últimas décadas do século XX e esta se massifica na transição para o século XXI. Ressaltamos o modo pela qual esta suposta "pós-modernidade" cobre manifestações amplas em segmentos os mais variados desde a música e o teatro, até as artes plásticas e visuais, além de combinar expressões culturais e tendências estéticas posteriores que se seguiram à "modernidade", reconhecida então, como declinante.

Cumpre-nos ressaltar também como as identidades eram estabelecidas na maioria das vezes através de acontecimentos fundadores ligados à apropriação de territórios ou aos movimentos de libertação, fato comum na América Latina. Sem falar no desenvolvimento de tradições e a construção, neste contexto, do Estado-nação, um dos interesses de pesquisa de Eric Hobsbawn. Esta expressão tanto se refere às tradições institucionalizadas, quanto àquelas que surgem de forma repentina e são capturadas como se fossem originais, mesmo que durem relativamente pouco. (HOBSBAWN, 1984, p. 13). Muitas vezes as tradições inventadas por elites políticas latinas para justificar a existência de suas nações foram usadas como recurso para firmar a posição de seus Estados durante o século XX.

Além disso, as sociedades nacionais tiveram como aliados até a década de 1950, o rádio e o cinema como narradores dos sentidos de identidade. Nas duas décadas seguintes, a televisão, a publicidade e os novos agentes das inovações tecnológicas ainda continuaram padronizando os padrões de consumo consolidando uma visão nacional na maioria dos países. A partir da década de 1980 a abertura da economia aos mercados globais reduziu o papel das culturas nacionais e dos referenciais tradicionais de identidade, como vimos na segunda seção.

$\mathrm{O}$ advento da internet e das redes sociais, embora aproximem pessoas, não possuem em seu "DNA" a obrigação da restituição dos laços locais ou posições de identidade regionais, pois operam também aproximações majoritariamente encapsuladas pelos símbolos transnacionais.

De qualquer modo, por cautela, precisamos lembrar que as artes plásticas, a literatura, o rádio e o cinema, como agentes midiáticos da modernidade ainda se mantêm como procedências do imaginário nacional, mas esses setores realizam a criação e a recepção da arte cada 
vez mais de forma desterritorializada na pós-modernidade. Uma prova disso são as exposições internacionais que substituem as particularidades de cada país por mostras de eixos culturais, como "cidades reinventadas" ou "paisagens culturais latinas", por exemplo. Pode-se apresentar um tema como "LUSA" que viaja pelos países de língua portuguesa, mostrando as origens de Portugal, ou mesmo uma feira tecnológica como Anima Mundi, que constrói uma narrativa mundial, a partir de mitos inteligíveis para uma audiência global.

A tendência para uma cultura de espetáculo multimídia, entretanto não tem impedido as culturas regionais de se manifestarem. Um exemplo disso, o cinema "global" de Hollywood separa espaços para coproduções latino-americanas ou para distribuição internacional, como "Central do Brasil", "Cidade de Deus" e "El Secreto de Sus Ojos", mas opera a produção ou a publicidade a partir de temáticas universais, como a violência e a pobreza, não raro fundamentadas na paisagem dramáticourbana comuns em qualquer lugar.

O curioso é que paralelamente a esse processo de desterritorialização das artes existem ações articuladas que conduzem a reterritorialização, originadas por movimentos sociais ou conduzidas por meios de comunicação regionais, que criam mercados de música, folclore e artes. Estabelecem também mixagens e desmassificações das formas de consumir que conduzem a modelos locais arraigados, como os que ocorrem com o conhecimento repassado por gerações sucessivas relacionadas à fabricação artesanal de panelas de barro em Goiabeiras Velha, no Espírito Santo, ou do samba de roda do Recôncavo Baiano. Podemos registrar ainda a recuperação patrimonial adotada nos núcleos históricos de Lima e Quito, este último caso, uma notável recuperação das identidades locais combinada com a melhoria das condições de infraestrutura, sem alterar significativamente a paisagem e recuperando suas singularidades artísticas e arquitetônicas. (FUNARI \& PELEGRINI, 2009, p. 54-58)

Para compreender o que estamos evocando é interessante delimitar uma pirâmide invertida para delimitar as influências multiculturais na América Latina, uma vez que em diferentes circuitos o predomínio dos símbolos transnacionais podem ser mais ou menos determinados. No estágio inferior da pirâmide menos influenciado e mais blindado em relação à globalização, estaria a cultura histórica, documentalizada, forjada em patrimônios tangíveis e intangíveis e que incluem os saberes, hábitos e redes sociais étnicas. Haveria um segundo estágio, o dos meios de comunicação de massa que voltados para lazer e informação, demarcam ainda uma nítida influencia da hegemonia americana, especialmente nas redes de TV por assinatura, combinada com sistemas 
de comunicação regionais como Televisa ou Globo que dispõem de recursos tecnológicos e humanos para motivar uma forte produção nacional em países como México e Brasil. O último estágio da pirâmide invertida, no topo e mais amplo, incluiria as plataformas digitais da web, computação nas nuvens, tecnologia de satélites, redes óticas e redes de entretenimento de rápida expansão (vídeostreaming e games) no qual se experimenta um nítido enfraquecimento das identidades nacionais.

Vamos chamar um autor aqui para confirmar a nossa proposição, mas com outro modelo. Para o antropólogo Arjan Appadurai (2004) conhecido pelos seus trabalhos sobre modernidade e globalização, é a imaginação, no sentido de Anderson $(1983)^{6}$, que centraliza agora todas as formas de ação, constituindo um fato social e sendo o principal componente da nova ordem global. Vivemos em mundos imaginados, e não apenas comunidades imaginadas.

A classificação de Arjun Appadurai ao invés de identificar tres estágios de reordenamento das diferenças e desigualdades, conforme propomos, prefere visualizar cinco processos atuais que atualizam a matriz tradicional das identidades até então centrada em nacionalismos e classes sociais.

$\mathrm{Na}$ "etnopaisagem" prevalecem os movimentos populacionais de imigrantes, turistas refugiados, exilados e trabalhadores sazonais; $\mathrm{Na}$ "tecnopaisagem" vemos os fluxos originados das tecnologias e corporações multinacionais transpostos em grande velocidade em fronteiras antes impenetráveis; No processo de "financiopaisagem" o capital global é intercambiado nos mercados de capitais e a especulação comercial se move nos mercados internacionais. Depois, ele destaca as "mediapaisagens", isto é, a distribuição da capacidade eletrônica para produzir e disseminar informações que fornecem repertórios de imagens e narrativas misturadas ao mercado e ao mundo das notícias e da política, tornando confusas as linhas divisórias entre as paisagens da realidade e da ficção. Por fim, as "ideopaisagens": conteúdos ideológicos politizados, iluministas, consistindo de ideias, termos e imagens, como liberdade, bem-estar, direitos humanos e democracia que transcendem as identidades particulares.

\footnotetext{
${ }^{6}$ Benedict Anderson, autor do livro Imagined Communities (Comunidades Imaginadas, 1983) define a nação como “(...) uma comunidade política imaginada” intrinsecamente limitada e, ao mesmo tempo, soberana. Segundo ele, a nação seria imaginada porque seus membros não se conhecem, contudo conseguem reter na mente a imagem da comunidade da qual participam. Isso significa que os limites de uma nação não existem na prática, mas seus indivíduos são capazes de criar tais fronteiras e imaginar seus membros.
} 
Fica claro que Appadurai associa a formação das identidades com os aspectos de consumo e fluxo informacional, mas compreendendo que imaginação tornou-se um campo organizado de práticas sociais. Os meios de comunicação de massa e as migrações têm um efeito fundamental sobre a obra da imaginação, sendo esta uma característica constitutiva da subjetividade moderna, isto é, os "sentimentos de identidade" de cada um. Então, o elemento decisivo das modernas formas de consumismo é o prazer, não o lazer ou a satisfação. O efêmero é a disciplina do consumidor moderno, uma vez que o consumo cria tempo mas o consumo moderno substitui a estética da duração pela estética do efêmero. Na maioria das sociedades seus rituais de passagem têm marcadores de consumo, organizados em torno da oferta de presentes.

Deduzimos então que os produtos transnacionais não são muito mais homogêneos do que se acredita, especialmente nos níveis mais baixos da pirâmide invertida ou nos processos da reordenaçao do que Appadurai denomina de “etnopaisagem”. Então, é de supor que alguns movimentos nascidos nas culturas populares latinas parecem resistir a essa transformação e estão mais dispostos a afirmar uma identidade revitalizada, do que negociá-la.

Assim parece se expressar também Martha Jares sobre aspectos presentes na literatura de cordel ligados aos processos de resistência da identidade cultural do povo sertanejo brasileiro. Jares em seu artigo "Resistência e identidade cultural na literatura de Cordel" (2010) discute sobre o papel que a literatura de cordel possui enquanto cultura subalterna na representação da cultura popular e na formação da identidade cultural do povo sertanejo.

Sabemos que através de processos de resistência, a ressignificação é feita de forma a retratar a cultura local a partir de elementos culturais, sociais, políticos e cotidianos, entretanto muitos desses modos de resolver as questões da identidade, como os que se revelam nos estudos de Jares, podem ser mostrar irreais no cenário latino cuja composição sociocultural é heterogênea e interage há séculos com a internacionalização, como visto anteriormente.

Imaginando ainda a nossa pirâmide invertida, há segmentos dissonantes dentro da faixa que supostamente seria incluída no extrato inferior, o histórico-documental, que se tornam menos resistentes aos apelos transnacionais. Por que ocorre isso? Esses movimentos percebem que a fundação da modernidade não substitui suas tradições, e uma das formas de reafirmar sua cultura é fazer concessões apropriando conhecimentos e recursos culturais modernos, a fim de resolverem suas demandas e necessidades, como vimos no caso dos indígenas mexicanos que 
comercializam seus suvenires aos turistas, mesmo que fique a dúvida sobre se esta negociação contribua efetivamente para que sejam cidadãos.

A dificuldade para uma negociação que resulte positiva para os movimentos que representam comunidades tradicionais, é que a globalização no dizer de Ortiz "se aplica à produção, distribuição e consumo de bens e de serviços organizados a partir de uma estratégia mundial, e voltados para um mercado mundial." Ainda se hesita em conferir um estatuto científico a essa entidade que deveria ser identificada como uma espécie de "mega-sociedade", trasformando as relações políticas, econômicas e culturais entre as partes que a constituem. (ORTIZ, 1986).

Esta "negociação cultural" não é exclusiva do século XX, acontece ao longo da trajetória de construção da modernidade. Como exemplo de um subgrupo que se distingue em meio a uma sociedade padrão por meios de expressão tradicionais, a escritora argentina Josefina Ludmer (1988), identificou a literatura "gauchesca" do século XIX um subgênero da literatura americana que tentou recriar a língua do gaúcho e contar o seu modo de vida. Esta literatura se preocupava em descrever a vida camponesa e seus costumes, identificando os tipos sociais da época: crioulos, índios, mestiços, negros e yankees. A literatura gauchesca caracterizou-se essencialmente pelo gaúcho como personagem principal. Suas ações se realizavam em espaços abertos como os pampas argentinos, mais imunes ao espaço industrializado de Buenos Aires que se firmava no século XIX como uma cidade de modelo europeu, notadamente de origem inglesa. Como negociar estas posições de identidade, firmadas no passado, neste novo contexto transnacional e pós-moderno?

Talvez Fredric Jameson (1991) possa nos ajudar nesta resposta. Ele argumenta que qualquer ponto de vista a respeito do pós-modernismo no campo cultural é simultaneamente uma posição política, implícita ou explícita, com respeito à natureza do capitalismo multinacional globalizado de nossos dias. Supomos então que qualquer arranjo nos espaços culturais superpostos pelas identidades deve levar isso em conta. Para Jameson o pós-modernismo indica a sobreposição entre as teorias do pós-modernismo e os novos paradigmas sociais que anunciam um tipo novo de sociedade, denominada sociedade pós-industrial. Na busca por uma resposta sobre os limites da negociação das identidades no ambiente de produção coletiva atual, identificamos um perigo: essa negociação entre identidades minoritárias e os monopólios de comunicação ou de finanças não está apenas no fato de se reconstituir de forma oblíqua a memória e a identidade destes grupos, mas no aparecimento da dissimulação durante e após a mediação. Deslocados agora do 
parlamento, dos sindicatos e das manifestações grevistas para os ambientes midiáticos transnacionais, a readequação dos signos nacionais fez surgir o ambiente da dissimulação, como substituto do símbolo idealmente representativo das causas, que até o início do século XX podia ainda ser realizada através da literatura, por exemplo, como no caso da cultura "gauchesca". O novo cenário do simulacro nos conduz para uma questão inevitável: o que sobra de confrontação racional e como as representações ficam extraviadas da sua função de defesa das identidades?

Em nosso ponto de vista, a decorrência imediata do simulacro é que a substituição dos conflitos de identidade por espetáculos pode fazer das manifestações sociais um produto semelhante aos videogames, quando as causas dos conflitos relacionadas a disputas por identidades e imaginários políticos ficam sublimados. A atração nos meios de comunicação tornouse rotineira, especialmente quando se trata da televisão, mas na internet o fenômeno vem se reproduzindo com dinâmica semelhante. Quando o espaço para a reflexão desaparece e ganham destaque as invasões de aeroportos, imagens de trajetórias de mísseis, bate-bocas entre parlamentares ou acusações bombásticas emitidas em encenações teatrais, parece confirmar que a lógica do lucro como objetivo das emissoras comerciais e, em decorrência, a visão da mídia como fonte prioritária de informação e entretenimento sublima os pensamentos críticos e limita uma maior expressividade daqueles querem ver mais que um fenômeno audiovisual. Por que se deveriam fazer perguntas sobre identidade se a televisão e os jornais eletrônicos que se pretendem instrumentos de registro tornam-se uma ferramenta de criação de realidade?

No caso específico da televisão, analisando o pouco espaço que o meio concede ao pensamento crítico, Pierre Bourdieu alertava para que essa ferramenta aparentemente democrática não se convertesse em instrumento de opressão simbólica. Em seu polêmico livro "Sobre a televisão", ele retrata as contradições e tensões do veículo:

A televisão é um instrumento de comunicação muito pouco autônomo, sobre o qual pesa toda uma série de restrições que se devem às relações sociais entre os jornalistas (...) que são também relações de conivência, de cumplicidade objetiva, baseadas nos interesses comuns ligados à sua posição no campo de produção simbólica e no fato de que têm em comum estruturas cognitivas, categorias de percepção e de apreciação ligadas à sua origem social. (BOURDIEU, 1997, p. 51)

Os responsáveis que monitoram o "real time" (índice instantâneo de audiência) possuem um modo particular de percepção ajustado às 
exigências objetivas do veículo, que talvez não seja partilhado, digamos, por indígenas urbanos que proponham espaço para suas demandas de reconhecimento identitário ou pelos "sem teto" que querem espaço urgente na mídia para seus pedidos por moradia. Em nosso ponto de vista, as relações de conivência e cumplicidade na televisão, ressaltadas por Bourdieu, impõem aos representantes dos discursos de identidade um senso de urgência adaptado ao meio TV e que somente pode ser capturado para dentro dele sob a forma de "revoluções no subúrbio", "choques com a polícia militar" ou em questões de comércio de rua, por exemplo.

Na América Latina, ao contrário da Europa, a televisão foi concebida na forma de um empreendimento comercial, não raramente patrocinado por capitais americanos, não se pensou na TV como serviço público, com algum tipo de responsabilidade social ou oportunidade de se dirigir ao cidadão, oferecendo instrumentos de reflexão e crítica. Não falamos aqui de uma "televisão europeia" isenta desta urgência e espetacularidade, próprias do meio, uma vez que a TF1 francesa, a BBC inglesa e tantas outras caminham na mesma direção, apenas quisemos demarcar a origem do processo da indústria da TV no continente latinoamericano que nasce sob forte influencia e financiamento estrangeiro, especialmente o tipo de produção imposta pelos conglomerados americanos.

\section{Considerações Finais}

Como constatamos, a história recente da América Latina sugere que há algo como desejo de comunidade que transcende a concepção da nação ou classe social, que se dirige para pertencimentos religiosos, étnicos e circuitos de consumo de massa e tenta encontrar, seja na TV, no jornal impresso e eletrônico, ou na internet, os melhores modelos de expressão e defesa de seus direitos.

Sabemos da limitação deste artigo quanto aos aspectos que se referem a estes novos sensos de pertencimento, preponderantemente na América Latina. Se escolhemos evidenciar a região, foi menos por encontrar particularidades exclusivas neste grande eixo geográfico do que explorar o caráter mais perverso no qual as identidades locais são sufocadas pelas redes de tecnologia e cultura transnacionais.

Permanecendo um pouco mais nesta linha que pretende estabelecer supostas pontes de ligação entre as demandas identitárias e os monopólios de comunicação, muitas vozes tentam estabelecer uma contradição à possibilidade de que o discurso das identidades locais seja 
capaz de se organizar junto às comunidades de consumidores. Então, sem parecer extremista, e com receio de certa simplificação, até pela limitação do espaço deste artigo, devemos atentar para três aspectos finais.

Em primeiro lugar, assim como Ortiz (1996, p. 104) já apontara, deve-se ter em mente que algumas corporações assumem um papel de protagonista da história na "americanização" da cultura mundial e não abrem mão desta posição, especialmente na América Latina. Ortiz observa que as relações sociais mundializadas no interior das quais fica difícil identificar a centralidade das coisas, mesmo em um suposto ambiente de maior abertura, não provoca uma partilha de significados compartilhados democraticamente e, portanto não pode significar também ausência de poder. Este artigo, entretanto não pretendeu analisar a perda da essência das tradições estabelecidas ou "inventadas" que são altamente aplicáveis para a compreensão do desenvolvimento da nação, dos nacionalismos, do Estado nacional ou dos símbolos nacionais, tão caros ao processo de formação dos Estados-nação na América Latina. Nosso intuito foi compreender as adaptações que determinados segmentos sociais descolados deste sentimento mais estável de suas identidades, tendo prevalecido até as últimas décadas do século $\mathrm{XX}$, fazem ou precisam fazer desde então, para conservar velhos costumes em condições novas e até mesmo para usar velhos modelos para novos fins, como táticas de negociação e recomposição para a preservação de suas identidades.

Em segundo lugar, defendida uma maior preponderância dos discursos subalternos, das minorias étnicas ou de gênero, é necessário ressaltar que os conflitos de identidade na América Latina, com mais frequência que em outras partes, não se dão apenas entre classes ou grupos, mas também se expressam em duas tendências culturais: uma espécie de negociação racionalizada, que tenta ser mais crítica e um simulacro consensual que se contenta com os sensos de urgência da indústria da comunicação, especialmente da televisão. Nesta negociação, o contato que políticos, instituições privadas e monopólios de comunicação fazem com a cultura popular se efetiva pela interação com ícones de comunicação de massa, reproduzidas também na internet, e não por meio de trocas de informação ou do exame de cada parte dos problemas populares.

Por último e não menos importante, constatamos como os monopólios de comunicação e as corporações internacionais uniformizam seus conteúdos e produtos porque visam aos mercados de consumo, correndose o risco de se fazer uso ordinário das imagens, produtos e serviços como fator de pressão simbólica para produzir "realidades", que evocam ideias ou representações, estimulam a construção de grupos e até evocam 
algum efeito de mobilização, como se fossem naturalmente originados destes grupos. Há implicações políticas e éticas aqui, mas devemos nos preocupar com a capacidade destas mensagens e produtos explorar sentidos de pertencimento a partir de posições racistas, preconceito com os estrangeiros, mitos de origem ou associações de gênero, cor e raça, mas que se expressam nos produtos comercializados (camisetas, suvenires, produtos de gastronomia, hotelaria, turismo, shows, videogames, novelas, eventos esportivos, seriados), de forma simulada, efêmera, próprios da produção coletiva internacional.

Um desafio para todos nós seria o de resgatar na América Latina essas questões culturais da modernidade e pós-modernidade, do mercado e da política tradicional, refletir sobre o real e o imaginário, símbolo e simulacro, globalização e negociação seletiva, a partir das comunidades, da sociedade civil e do Estado, num multiculturalismo democrático.

\section{Referências}

ANDERSON, Benedict. Comunidades Imaginadas. São Paulo: Cia. das Letras, 2008.

APPADURAI, Arjun. Dimensões culturais da globalização. Lisboa: Teorema, 2004.

BLUMER, Herbert. Psicologia social. In: O homem e a Sociedade: Uma Essencial Introdução à Ciência social . (Man and Society: A Substantive Introduction to the Social Science). New York: PrenticeHall, 1937.

BOURDIEU, Pierre. Sobre a televisão. Rio de Janeiro: Jorge Zahar Editor, 1997.

CANCLINI, Nestor Garcia. Consumidores e Cidadãos. Rio de Janeiro: Editora UFRJ, 2006.

GIDDENS, Anthony. As conseqüências da modernidade. São Paulo: Unesp, 1991

FRANCO, Augusto. "Globalização e neoliberalismo". Disponível em: www.contexto3.blogspot.com.br. Acessado em 26/12/2013.

FUNARI, Pedro. PELEGRINI, Sandra C. Araújo. Patrimônio Histórico e Cultural. 2 ${ }^{\text {a }}$. Ed. Rio de Janeiro: Jorge Zahar Editora, 2009. 
HALL, Stuart. "Minimal Selves". In: Identity: the real Me. ICA document 6. Londres: Institute for Contemporary Arts, 1987.

HALL, Stuart. A identidade cultural na pós-modernidade. Rio de Janeiro: DP\&A Editora, 2006.

HOBSBAWN, Eric. In: HOBSBAWN, Eric. RANGER, Terence. A invenção das tradições. Rio de Janeiro: Paz e Terra, 1984.

JAMESON, Fredric. Pós-modernismo. Rio de Janeiro: Editora Ática, 1991.

JARES, Martha. Resistência e Identidade cultural na literatura de cordel. Artigo de conclusão de pós-graduação. Universidade de São Paulo, 2010.

KEEGAN, Warren J. \& GREN, Mark C. Princípios de Marketing Global. São Paulo: Saraiva, 2006.

LUDMER, Josefina. El genero gauchesco. Un tratado sobre la patria. Buenos Aires: Sudamericana, 1988.

MEAD, George Herbert. Mind, Self, and Society. Chicago: University of Chicago Press, 1934. Ed: Charles W. Morris.

ORTIZ, Renato. Mundialização e Cultura. São Paulo: Brasiliense, 1996.

PEÑA, Guilhermo de la \& TORRE, René de la. "Identidades urbanas al fin del milenio". Ciudades. Mexico, n.22, abr/jun 1994.

RIBEIRO, Renato Janini. "Educação para melhorar a política". Disponível em: http://beneviani.blogspot.com.br. Acessado em 22/12/2013. 